\title{
Final steps in the feedback regulation of human glucocorticoid receptor gene and role of nuclear protein phosphatase $2 \mathrm{~A}$
}

\author{
Manjapra Variath Govindan* and Carl Seguin \\ *Correspondence: Manjapra-variath.Govindan@fmed.ulaval.ca \\ Department of Molecular Biology, Biochemistry and Pathology, Faculté de médicine, Université Laval, \\ Québec (Québec) Canada G1K 7P4.
}

\begin{abstract}
The feedback regulation of the human glucocorticoid receptor gene by glucocorticoid receptor-hormone complexes involves the recruitment of the nuclear phosphatase, PP2A. The PP2A holoenzyme consists of a structural subunit A, a catalytic subunit $\mathrm{C}$, and a variable regulatory subunit B or PPP2R3C, with distinct specificities. Our goal was to investigate the nature of the interaction between glucocorticoid receptor-hormone complex and PPP2R3C in the regulation of the glucocorticoid receptor gene involving the feedback regulatory element. Co-immunoprecipitation assays revealed interaction of glucocorticoid receptor with PPP2R3C only in the presence of ligand. In mammalian two-hybrid assays, we expanded our investigation using mutations of specific serines in the AF-1 region of the glucocorticoid receptor and deletion mutants of PPP2R3C. We determined which of the two nuclear recognition motifs in PPP2R3C interacted with glucocorticoid receptor. Following purification of CREB and PPP2R3C, we performed in vitro de-phosphorylation experiments and demonstrated the direct role of glucocorticoid receptor dexamethasone complexes in recruiting nuclear PP2A complexes containing PPP2R3C to dephosphorylate CREB-P. Based on these results, GST-GR proteins were produced and in GST pull-down assays we determined that it was indeed the hormone binding domain as well as amino acids 76-262 in the AF-1 of the GR that interacted with PPP2R3C. Protein-protein interaction assays using GST-GR fusion proteins revealed that Ser 211 and Ser 226 in the AF-1 domain of the GR were contacted by PPP2R3C in the presence of dexamethasone. PPP2R3C mediated suppression of luciferase reporter gene activity in HeLa cells treated with dexamethasone and Okadaic acid. Knocking down PPP2R3C enhanced GR level in Western blots. In immunoprecipitation studies, GR expression was not inhibited in PPP2R3C knockdown cells. Indeed, luciferase reporter activity containing feedback regulatory element of GR gene increased in the presence of cAMP and dexamethasone. This suggested that PPP2R3C prevented CREB-P de-phosphorylation and GR recruitment, a conclusion supported by the fact that rescue of PPP2R3C restored function. In conclusion, our studies show the role of PPP2R3C in GR-mediated negative regulation of target genes where knocking down PPP2R3C increased GR level. Glucocorticoids are widely used in cancer therapy and resistance to treatment is a common occurrence. Our understanding of the data presented here could be useful in designing treatment regimens for patients.

Keywords: PPP2R3C, glucocorticoid receptor, feedback regulation, nuclear phosphatase, CREB-P de-phosphorylation, signal transduction, molecular cloning, ligand specificity, protein-protein interaction, transcription repression
\end{abstract}

\section{Introduction}

Glucocorticoids regulate gene transcription through diverse pathways [1-3], some of which are positive involving a functional interaction between the glucocorticoid response element (GRE) and CRE [4], while others involve negative glucocorticoid response elements (nGREs) [3] to directly suppress expression of target genes [5]. The functional response of the regulation of GR gene transcription is located -2846 bp upstream of the Cap site of the GR gene promoter [6]. More precisely, a feedback regulatory element (FBRE) is located between -1532 bp and $-971 \mathrm{bp}$, which contains two nGREs and two CREs [7]. Activation of the GR is a multi-step process that requires among others, displacement of proteins, recruitment of co-regulators and phosphorylation of specific residues such as serines ( Figure 1A), all dictated by tissue specificity. Specific serines such as Ser113, 211,226 , and 241 in the GR AF-1 region are targets of various kinases [8]. The ligand activated GR affects the phosphorylation status of CREB in CAMP stimulated corticotropinreleasing hormone-reporter expression in AtT-20 cells [9]. A recent report shows that dephosphorylation of CREB-P is dependent on dexamethasone (DEX) bound GR [7] and involves a nuclear protein phosphatase [10]. PP2A, one of the four major serine/ threonine phosphatases, is implicated in the negative control of cell growth and division, cell cycle progression, DNA replication, transcription and translation [11].

The PP2A holoenzyme is a heterotrimeric protein composed of a structural subunit $A$, a catalytic subunit $C$, and a regulatory subunit $B$ [12]. The regulatory subunit $B$ is encoded by a diverse set of genes that have been grouped together into the B/PR55, $B^{\prime} /$ PR61 and B"/PR72 families [11] that confer distinct enzymatic specificities and intracellular localizations to the holoenzyme. The expression and structure of these proteins have been analyzed in detail but very little is known about their function. We have focused on the regulatory subunit B (PPP2R3C), a $50 \mathrm{kDa}$ protein, $1359 \mathrm{bp}$ long, encoding 453 aa that is highly expressed in glucocorticoid target tissues. PPP2R3C contains 


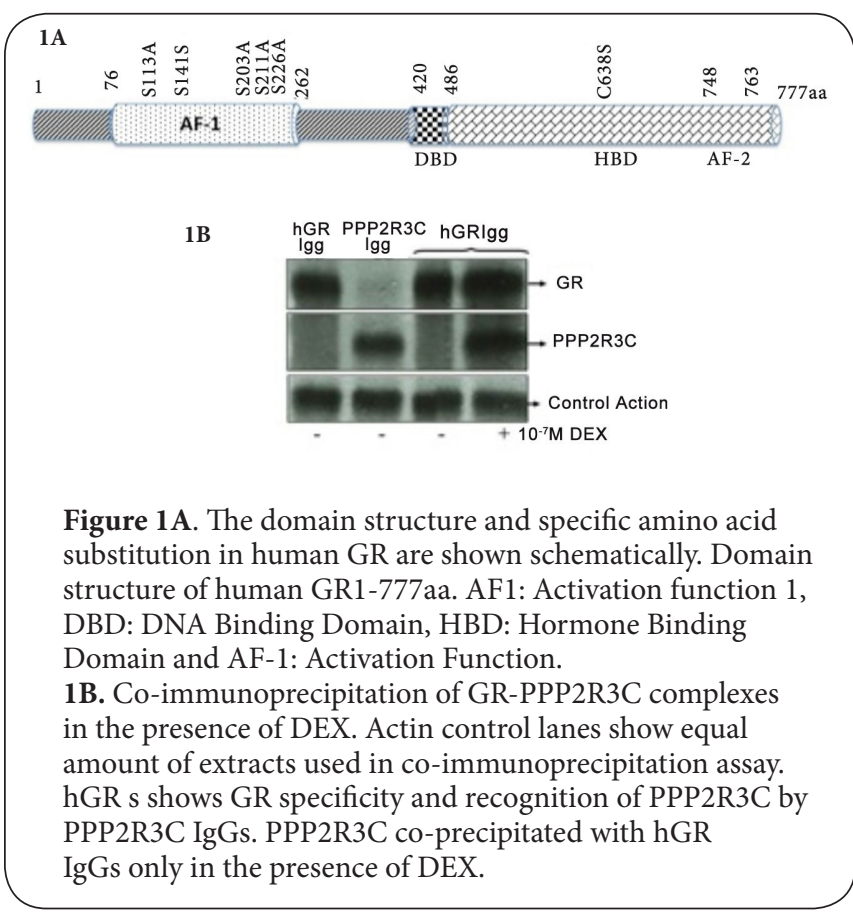

two signature motifs for interaction with nuclear receptors, which makes PPP2R3C a prime candidate for this study. In this paper, we show that GR-DEX complexes recruit PPP2R3C to de-phosphorylate CREB-P, a process in which the FBRE has a role. The association of GR with PPP2R3C is ligand dependent and the kinetics follow the time course of ligand treatment in GR gene regulation by GR and de-phosphorylation of CREB-P.

\section{Experimental procedures \\ Molecular Cloning of human putative phosphatase subunit}

Total RNA prepared from T47D cells treated with vehicle or $1 \mu \mathrm{M}$ DEX was purified by oligo-dT cellulose chromatography. $1 \mu \mathrm{g}$ RNA samples were used for the Mate \& Plate cDNA library construction using the cDNA library construction kit from ClonTech in Y187 Yeast Strain. The GAL4DNA-BD containing the entire human GR1-777 bait was cloned in frame into the three-hybrid vector pBidge (ClonTech). The T47D cDNA libraries were screened, clones were analyzed for specificity and relevant cDNA clones were analyzed for insert length (not shown). The mRNA sequences were analyzed in GenBank EST database to identify putative PP2A regulatory subunit amino acid sequences. Of the 27 specific cDNA clones selected, 5 contained common mRNA sequences which were identical to the PP2A regulatory subunit B "PPP2R3C" Gene Bank Accession \# NM_017917. Full-length cDNA of AY157304.1 map "14q13" containing LWFLL (99-103) and LDDLL (249253) was purchased from Open Biosystems in pSports6 vector. Deletion mutants aa 103-453 and aa 253-453 were generated by PCR and cloned into pVP16 vectors to generate pVP16 PPP2R3C 1-103 and pVP16 PPP2R3C 1-253 expression vectors.

\section{Mammalian two hybrid assays}

The Mammalian Matchmaker was performed using the TwoHybrid Assay Kit from Clontech, USA in HeLa cells. The pM cloning vector is used to generate fusions of GRwt and its $\mathrm{N}$-terminal serine mutants S113A, S141 A, S203A, S211A and S226A respectively in the GAL4 DNA-BD vector with primers (IDT DNA, USA) designed for GR fusion (Table 2). The generation of hGR mutants S113A, S141A, S203A, S211A and S226A were described before [7]. Similarly, pVP16 is used to construct fusions of PPP2R3C, PPP2R3C1-103 and PPP2R3C1-253 deletion mutants were amplified using primers (Table 2), digested with EcoRV+Xba1 and cloned into pVP16 vectors at Sma1+Xba1 vector, to an AD derived from the VP16 protein of herpes simplex virus. pG5-Luciferase is a reporter vector which contains the luciferase gene downstream of five consensus GAL4 binding sites and the minimal promoter of the adenovirus E1 b gene. The minimal E1 b promoter will not express significant levels of the luciferase gene, so background is low in the absence of activation from the GAL4 sites. HeLa cells were plated into 6 well plates and co-transfected with pM $(0.1 \mu \mathrm{g}), \mathrm{pVP} 16(0.1 \mu \mathrm{g}), \mathrm{pG} 5$ luciferase $(0.1 \mu \mathrm{g})$ and $0.1 \mu \mathrm{g}$ of internal control, ss-galactosidase expression vector. The transfectants were treated with 100nM DEX as indicated and continued incubation for 36 hours. Cell extracts were prepared in $50 \mu \mathrm{l}$ of luciferase extraction buffer from Promega containing complete protease inhibitor from Roche. ss-galactosidase activity was determined in $10 \mu \mathrm{l}$ aliquots of the extract and luciferase activity was determined extracts containing $10 \mathrm{U}$ of ss-galactosidase activity. The Mammalian Two-Hybrid Assay is a powerful tool for functionally analyzing that interaction using deletional or site-directed mutagenesis. The Mammalian Matchmaker Two-Hybrid Assay is also useful for confirming the relevance of protein-protein interactions identified via yeast two-hybrid screens. Such confirmation eliminates the possibility of a false positive that is an artifact of working in yeast cells.

\section{PPP2R3C antibody characterization}

Polyclonal antibodies against PPP2R3C synthetic peptide NH2-Cys Pro Asn Lys Lys Lys Ser Glu Gln Glu Leu Lys Asp Glu Glu-COOH coupled to keyhole haemocyanin, were generated commercially by GenScript. HeLa, MCF-7, HepG2, T47D, LNCaP and LU-19 cells were grown in medium supplemented with $10 \%$ FBS to $80 \%$ confluence and harvested with the aid of a rubber policeman, washed twice with ice cold phosphate buffered saline (PBS) and resuspended in $500 \mu \mathrm{l}$ of a buffer containing $50 \mathrm{mM}$ Hepes (pH 7.4), $100 \mathrm{mM} \mathrm{NaCl}, 0.25 \mathrm{mM}$ EDTA, 1 mM dithiothrietol, 10\% Glycerol, 0.5\% Nonidet NP40, 1 mM PMSF and complete protease inhibitor cocktail (extraction buffer). Following sonication, the cell extracts were clarified by centrifugation at 15,000 rpm for $15 \mathrm{~min}$ at $4^{\circ} \mathrm{C}$. Aliquots of $25 \mu \mathrm{g}$ of total proteins were diluted with equal volumes of $2 \times S D S$ sample buffer and size fractionated on $12 \%$ SDS polyacrylamide mini-gels by electrophoresis 
Table 1. Primers sequences used to clone full-length PPP2R3C cDNA. The table includes the knockdown sequences of oligonucleotides used for RNAi of PPP2R3C.

\begin{tabular}{ll}
\hline PPP2R3C oligonucleotides & \multicolumn{1}{c}{ knockdown sequences } \\
\hline PPP2R3C Forward & 5'-GGGGGAGATCTCCACCATGGACTGGAAAGAAGTTCTTCGTCGGCGCCTA-3' \\
PPP2R3C Reverse & 5'-GTGCTTCTAGAGGATATCTCACTCGAGTGTATCATCAAGGTCTGCAGAGTT-3' \\
PPP2R3C Silencer A1 & 5'-GATCCCTCTCACGCTATGGAACAGTTCAAGAGACTGTTCCATAGCGTGAGAGTTA-3' \\
PPP2R3C Silencer A2 & 5'-AGCTTAACTCTCACGCTATGGAACAGTCTCTTGAACTGTTCCATAGCGTGAGAGG-3' \\
PPP2R3C Silencer B1 & 5'-GATCCCAGAGAGGCTCTTGTTGCATTCAAGAGATGCAACAAGAGCCTCTCTGTTA-3' \\
PPP2R3C Silencer B2 & 5'-AGCTTAACAGAGAGGCTCTTGTTGCATCTCTTGAATGCAACAAGAGCCTCTCTGG-3' \\
\hline
\end{tabular}

with pre-stained molecular weight markers (New England Biolabs) Western blotted as described before using antiGR IgGs and anti-PPP2R3C lgGs, using anti-actin as internal control. For immunoprecipitation assays, the cells growing in log phase in $100 \mathrm{~mm}$ Petri dishes were transferred into medium without methionine for $24 \mathrm{~h}$ before adding ${ }^{35} \mathrm{~S}$-methionine containing DMEM and grown in the labeling medium for $36 \mathrm{~h}$ before collection. The labeled cells were washed several times with ice cold PBS and re-suspended in $250 \mu \mathrm{l}$ extraction buffer, sonicated and clarified by centrifugation. Aliquots of $10-25 \mu \mathrm{g}$ of total cell extracts were used for immunoprecipitation using Protein $\mathrm{G}$ magnetic beads from Active Motif. The immunoprecipitates were boiled in SDS sample buffer and analyzed by SDS polyacrylamide gel electrophoresis followed by fluorography using Enhancer. The dried gels were autoradiographed using Kodak Biomax films and intensifying screens.

\section{Co-immunoprecipitation of GR and Western blotting using PPP2R3C IgGs}

HeLa, HeLa-GR and T47D cells were treated with various ligands as indicated and whole cell extracts were used for the immunoabsorption of GR on GR-IgG-Sepharose beads. The bound proteins were dissociated in SDS sample buffer, resolved on $12 \%$ SDS gels by electrophoresis. The gels were blotted onto Immobilone-P membranes and probed using control pre-immune, PPP2R3C and GR antibodies. To visualize the association of PPP2R3C, the Western blot was cut in stripes pertinent to the region of the factors and probed with lgGs against GR, PPP2R3C and actin respectively. Actin IgG was used as internal control.

\section{GR specificity of CREB-P de-phosphorylation}

The de-phosphorylation assay was performed using CREB--32P and GST GR captured PP2A as previously described [7]. IgGs against actin (SC-7210); CREB (SC-58); CREB-1 (Ser-133) (SC7978) were from Santa Cruz Biotechnologies. Similar assays were performed for the de-phosphorylation by PP2A and okadaic acid (OKA) inhibition using CREB-32P in solution. Identification of PPP2R3C subunit associated with GRDEX in CREB-P de-phosphorylation in vivo: HeLa, HeLa-GR, T47D and HepG2 cells were grown to $80 \%$ confluence treated with various ligands as described before. Whole cell extracts were prepared and GR, PPP2R3C and actin as control were precipitated using specific IgGs as described before. For in vitro CREB-P de-phosphporylation analyses, $C R E B-{ }^{32} P$ was purified and the assay performed as described previously. Briefly, 3,000 cpm of ${ }^{32}$ P-CREB was incubated with increasing amount of GST-hGR [7] in the presence of 10ng of purified PPP2R3C expressed in bacteria either in the absence or in the presence of 100nM DEX. The complexes were reconstituted with $10 \mu \mathrm{g}$ of whole cell extract from exponentially growing T47D cells grown in the absence of ligands. The quantity of phosphorylated CREB was determined by immunoprecipitation using polyclonal anti-CREB-P antibodies and protein $G$ magnetic beads. Beads were washed, bound complexes were eluted using $100 \mu \mathrm{I}$ SDS sample buffer and radioactivity was counted. Experiments were repeated a minimum of three times before plotting the results.

\section{Expression of GR, CREB and PPP2R3C in bacteria and GST Pull-Down}

CREB, CREB-133 (dominant negative mutant of the human CREB protein that contains a serine to alanine mutation corresponding to amino acid 133), GR WT and PP2A cDNAs were cloned into PRSET vectors and fusion proteins purified as described [7]. Purified bacterially expressed CREB and CREB-133 were phosphorylated essentially as described [7] with minor modifications. GST GR wt, GST-GR ${ }^{\mathrm{s}} 113_{\mathrm{A}^{\prime}}$ GST-GR ${ }^{\mathrm{s}} 141_{\mathrm{A}^{\prime}}$ GST-GR ${ }^{\mathrm{s}} 203_{\mathrm{A}^{\prime}}$ GST-GR ${ }^{\mathrm{s}} 211_{\mathrm{A}}$ or GST-GR ${ }^{\mathrm{s}} 226_{\mathrm{A}}$ were expressed in E. coli BL21 cells and prepared by standard methods. The GST fusion proteins of GRwt, $\mathrm{GR}_{1-420^{\prime}} \mathrm{GR}_{\mathrm{DBD}}$ and GR HBD (Table 2) were generated by PCR amplification, digested with BamH1 and EcoR1, purified by agarose gel electrophoresis and cloned into PGEX 2TK vector at the BamH1-EcoR1 sites. The GST fusion proteins were induced using $1 \mathrm{mM}$ isopropylthiogalactopyrranoside (IPTG). $2 \mu \mathrm{g}$ of the crude bacterial extract containing the GST fusion proteins were incubated with in vitro ${ }^{35} \mathrm{~S}$-methionine labeled PPP2R3C by transcription and translation using TNT Quick system (Promega, USA). The bound complexes were purified using glutathione-Sepharose as described [7] and analyzed by SDSpolyacrylamide gel electrophoresis and autoradiography. In the in vitro protein-protein assay controls included extracts from GST control and extracts containing the intact GRHBD in the absence and presence of $100 \mathrm{nM} \mathrm{DEX}$ to demonstrate 
Table 2. Sequence of oligonucleotide primers used for the amplification of PPP2R3C cDNA and derivatives to clone into pVP16 and construction of chimera. The sequence of human GR cDNA primers used for cloning the N-terminal AF- 1 serine mutants into pGEX vectors and construction of PPP2R3C-GRDBD and GRDBD-PPP2R3C chimera are also shown.

\begin{tabular}{|c|c|}
\hline Primer & Sequence \\
\hline $\begin{array}{l}\text { PPP2R3C pVP16 \& } \\
\text { Fusion Forward }\end{array}$ & 5’-GGGGGGAGATCTCGAGGATATCACCATGGACTGGAAAGAAGTTCTTCGTC-3’ \\
\hline $\begin{array}{l}\text { PPP2R3C pVP16 \& } \\
\text { Fusion Reverse }\end{array}$ & 5’-GGTCTAGATCAAGATCTCTCGAGTCATGTATCATCAAGGTCTGCAGAGTTTTCACTGTC-3' \\
\hline $\begin{array}{l}\text { PPP2R3C } \\
\text { pVP16 Reverse }\end{array}$ & 5’-TCGAGATCTATGGGATCCCCAGCAAAAACCATAAGTTCTGTAATTCTTCATT-3' \\
\hline $\begin{array}{l}\text { PPP2R3C } \\
\text { pVP16 Reverse }\end{array}$ & 5'-TCGAGATCTATCCAATAAATCACAAGGAAGCAGCATGC-3' \\
\hline $\begin{array}{l}\text { PPP2R3C COOH } \\
\text { Fusion Reverse }\end{array}$ & 5’-GGGGATATCTCTAGACTCGAGACATGTATCATCAAGGTCTGCAGAGTTTTCACTGTC-3’ \\
\hline hGR 5' Primer & 5'-GGCTCGAGGGATCCTCTAGAGAATTCACCATGGACTCCAAAGAATCATTAACTCCTGGTAG-3' \\
\hline hGR 3' Primer & 5’-GGCTCGAGGATCCTCTAGAGAATTCTCACTTTTGATGAAACAGAAGTTTTTTGATATTTCC -3' \\
\hline $\begin{array}{l}\text { hGR DBD NH } \\
\text { Fusion Forward }\end{array}$ & 5’-GGATATCCGAATTCCTCGAGACCATGGCTTCAGGATGTCATTATGGAGTCTTAACT -3’ \\
\hline $\begin{array}{l}\text { hGR DBD } \\
\mathrm{NH}_{2} \text { Fusion Reverse }\end{array}$ & 5’-GGGGTCTAGATCTCACTCGAGACAGGTTTCTTGTGAGACTCCTGTATGGGCCTGCTG -3’ \\
\hline $\begin{array}{l}\text { hGR DBD COOH } \\
\text { Fusion Forward }\end{array}$ & 5’-GGGGAGATCTCGAGATGGCTTCAGGATGTCATTATGGAGTCTTAACT-3’ \\
\hline $\begin{array}{l}\text { hGR DBD COOH } \\
\text { Fusion Reverse }\end{array}$ & 5’-CTCGAGCTCGGGAGATCTTCAGGTTTCTTGTGAGACTCCTGTATGGGCCTGCTG -3’' \\
\hline
\end{tabular}

the ligand and domain specificity. The CDNA of PPP2R3Cwt was cloned into PGEX and pRSET vectors inframe and expressed using BL21 cells and purified. Full-length wild type and substitution mutants of ${ }^{35} \mathrm{~S}$-methionine labeled factors were synthesized by in vitro transcription and translation (TNT Promega Corp., Madison, WI). Equivalent amounts of GST or GST-fusion proteins were used in vitro binding assays as previously described. Production and purification of GST GR fusion proteins were as described [7]. Aliquots of $25 \mathrm{ng}$ of purified GST GRwt and mutants or control GST were incubated with vehicle or with 100nM DEX prior to incubation with ${ }^{35}$ S-Methionine labeled PPP2R3C synthesized using TNT Quick system (Promega) and $0.5 \mu \mathrm{g}$ of pcDNA PPP2R3C. The GST GR bound PPP2R3C was separated using GST Magnetic beads and separated by electrophoresis on $12.5 \%$ acrylamide gels. The radioactive bands were visualized by treatment of the gels with Enhancer and autoradiography.

\section{Domain specific interaction of PPP2R3C and CREB-P de-phosphorylation}

HeLa cells were co-transfected with $0.5 \mu \mathrm{g}$ each of GRwt, $\mathrm{GR}^{\mathrm{Ser}} 113_{\mathrm{Ala}}$ and $\mathrm{GR}{ }^{\mathrm{Cys}} 638_{\text {Ser }}$ in the presence of $0.5 \mu \mathrm{g}$ of control vector without insert or PCMV Sport6 PPP2R3C. The transfectants were washed and treated with vehicle or $100 \mathrm{nM}$ DEX for $4 \mathrm{~h}$. Whole cell extracts were prepared as described and incubated with $3,000 \mathrm{cpm}$ of ${ }^{32} \mathrm{P}$-CREB. CREB-P was immunoprecipitated using anti-CREB-P antibodies and protein G. Pre-immune IgG served as control to define the specificity of CREB-P IgGs and protein complexes were dissociated by boiling for $5 \mathrm{~min}$ and analyzed by SDS-PAGE. Immunoprecipitated actin in extracts was used control to standardize.

\section{Knockdown of PPP2R3C in HeLa cells}

Two different sets of silencer sequences (Table 1) were assembled and inserted into pCMVSilencer4. 1 neo vector. HeLa cells were selected with G418 following transfection with controls and pSilencer vectors, selected using $\mathrm{G} 418$ and resistant colonies were amplified in G418 containing medium. Immunoblotting was performed with extracts from knockdown cells using GR IgGs. Immunoprecipitation with PPP2R3C knockdown and rescue of GR in PPP2R3C knockdown cells were essentially as described.

\section{Construction of GRDBD-PPP2R3C and PPP2R3C- GRDBD chimeras}

Human GR DNA-binding domain (DBD) containing 66 amino acids (EcoR1-EcoRV) was fused to the PPP2R3C subunit CDNA (EcoRV-Xba1) in-frame using primers (Table 2) and cloned into 5'-EcoR1-Xba13' (GR DBD -PPP2R3C fusion) digested pcDNA1 vector. The PPP2R3C fragments flanking 5'EcoRV-Xho1-3' and GR DBD fragment flanking 5'-Xho1-Xba1-3' and cloned into pcDNA 1 EcoRV-Xho1 (PPP2R3C-GRDBD fusion) vector. All amplified fragments were digested with respective restriction 


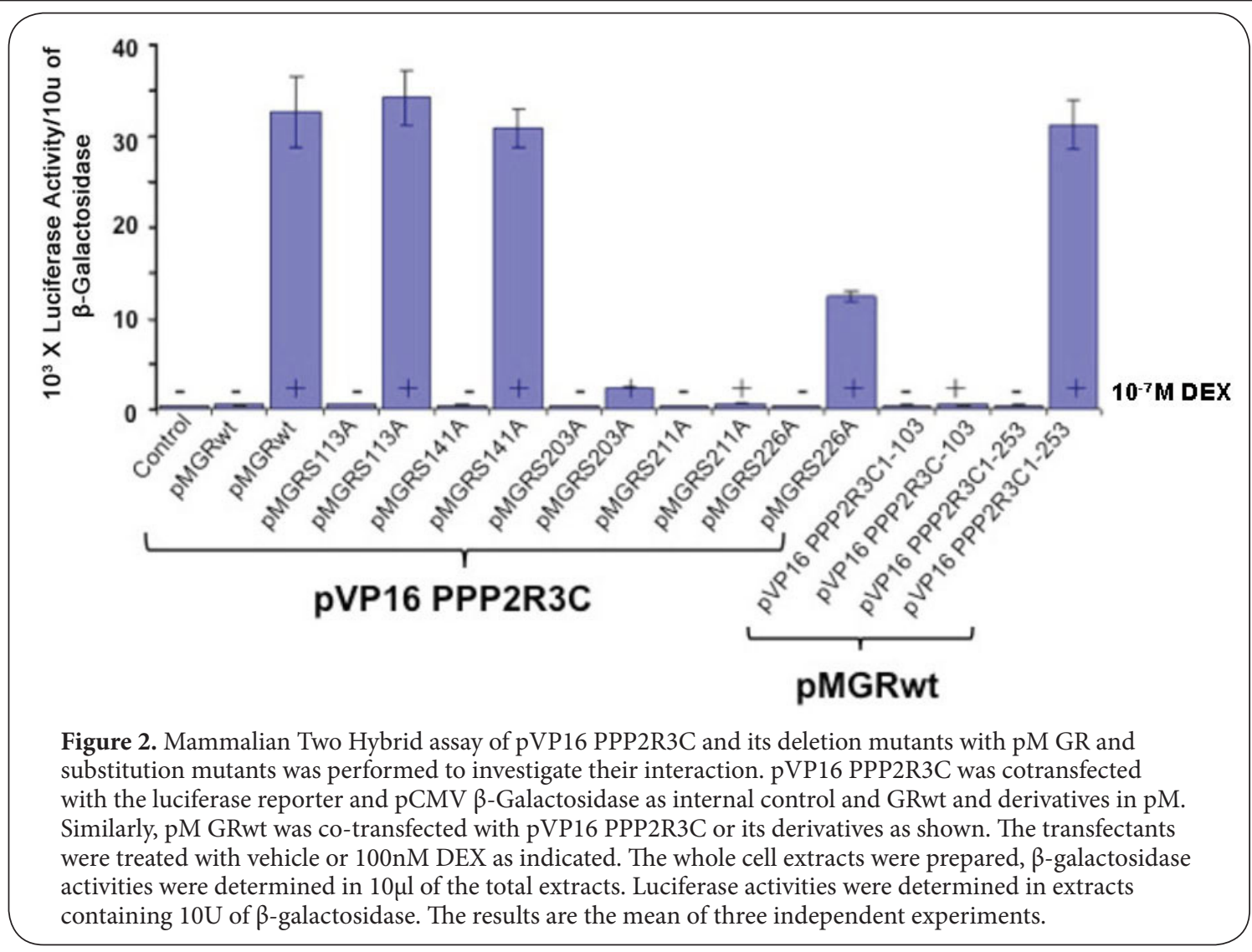

enzymes and purified by agarose gel electrophoresis before ligation reaction. Sequences of the fusion constructs were confirmed by DNA sequencing.

Trans-repression of GR gene feedback regulatory element (7) FBRE-tk Luciferase by PPP2R3C-GRDBD expression and Okadaic acid de-repression

5'CTCGAGCACCGGGAACTGGACG ${ }_{\text {nGRE }}$ CGGGCCCTGGCCGGGGTG-

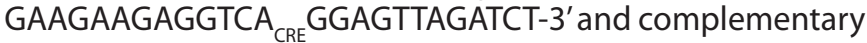
oligonucleotide (sequence derived from hGR gene feedback regulatory element, FBRE) were annealed and ligated into pGL4.14tk Luciferase at the Xho1-Bglll site. The sequence of the reporter was confirmed by DNA sequencing. The reporter vector was co-transfected with ssgalactosidase expression vector as internal control with pCDNA1 hGRwt or pCMV Sport6 PPP2R3C or the pcDNA1 PPP2R3C-hGRDBD chimera. The transfectants were treated with ligands as shown for $24 \mathrm{~h}$. Whole cell extracts were prepared and ss-galactosidase activity determined in aliquots of the extracts. Extracts containing $10 \mathrm{U}$ of ss-galactosidase were used for Luciferase assy. The results are the mean of three independent experiments.

\section{Transfection and selection of cells with G418}

Hela cells were plated in 6-well plates and transfected using $1 \mu \mathrm{g}$ purified plasmids using GenJuice. The cells were supplemented with selection medium containing G418
(InVitrogen) $12 \mathrm{~h}$ post transfection and selection continued until the appearance of colonies (4-6 weeks). Six colonies were isolated with the help of a pipette tip held under a microscope, re-suspended in selection medium and grown in $25 \mathrm{ml}$ culture flasks to confluence. For immunoprecipitation and transactivation analyses, cells were further amplified in selection medium in $250 \mathrm{ml}$ culture flasks.

\section{Results}

GR AF-1 domain interacts with specific amino acids of PPP2R3C in a ligand-dependent

To determine if the ligand bound GR physically interacted with PPP2R3C, we performed coimmunoprecipitation assays with GR-specific antibodies. Actin was used as a control to standardize protein levels (Figure 1B). GR IgGs coimmunoprecipitated with PPP2R3C only in the presence of DEX demonstrated by co-immunoprecipitation followed by Western blotting (Figure 1B) in favor of the hypothesis that GR and PPP2R3C formed complexes in vivo and that the complex formation was ligand dependent.

We expanded our investigation by testing the ability of GR WT, and and GR ${ }^{\text {Ser } 113, ~}{ }^{\text {Ser } 141, ~}{ }^{\text {Ser } 203, ~}{ }^{\text {Ser }} 211$ and ${ }^{\text {Ser }} 226$ (Figure 1A), to interact with PPP2R3C in mammalian two-hybrid assays and to determine which nuclear receptor recognition motif in PPP2R3C interacted with GR (Figure 2). Changing either Ser 113 or Ser 141 to alanine did not affect the ability of the 
$3 A$

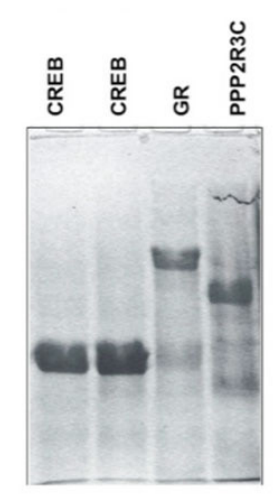

3B

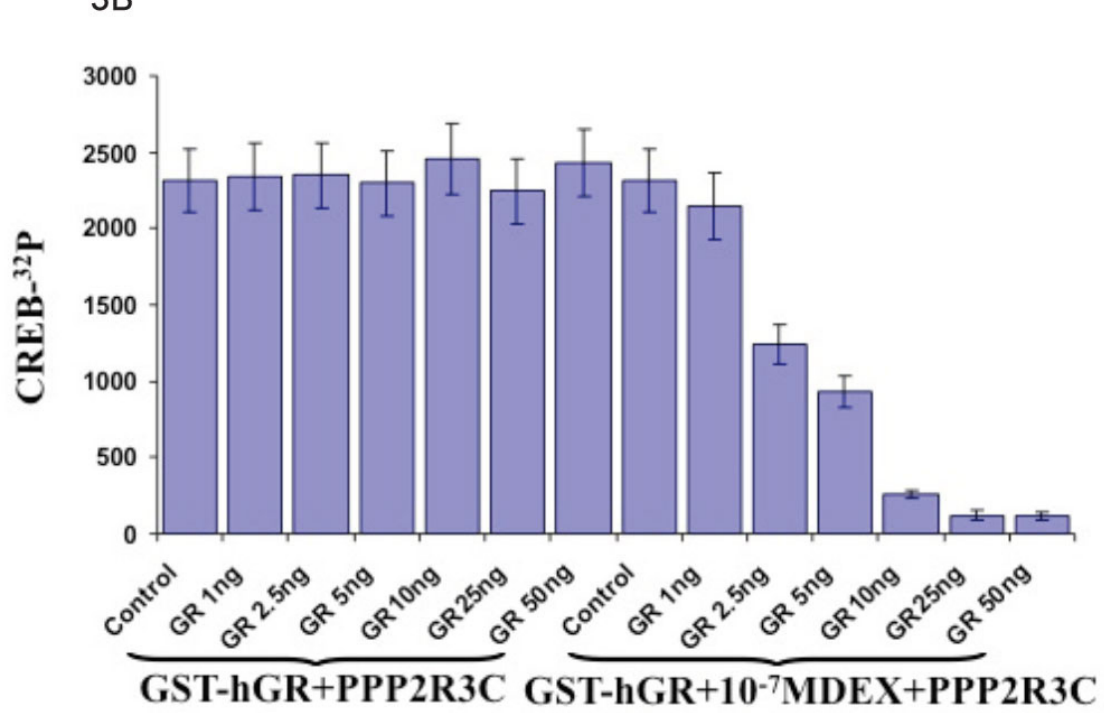

Figure 3A. Expression of GR WT, CREB, CREB-serine133, and PPP2R3C in bacteria. The factors were cloned into pRSET vector and fusion proteins were purified for in vitro binding and reconstitution assays. Fusion proteins CREB (lane 1), CREB-133 (a mutant variant of the human CREB protein that contains a serine to alanine mutation corresponding to amino acid 133, lane 2), GRwt (lane 3) and PPP2R3C (lane 4) respectively were induced with IPTG and purified as described Experimental Procedures. The CREB was phosphorylated as described and used for in vitro de-phosphorylation assays. 3B. De-phosphorylation of CREB-P by GST-GRDEX bound PPP2R3C reconstituted PP2A complexes from T47D extract: CREB-P de-phosphorylation was performed in the absence of $100 \mathrm{nM}$ DEX (Lanes 1-7) and in the presence of DEX (Lanes 8-14). The quantity of phosphorylated CREB was determined by immunoprecipitation using polyclonal anti-CREB-P antibodies and counting the 32P-radioactivity in immunoprecipitates. Experiments were repeated a minimum of three times before plotting the results. Controls without ligand and with ligand treatments are shown for reference. Extracts prepared from T47D cells in the absence of ligand served as control.

GR to interact with PPP2R3C when compared with GRwt. In contrast, luciferase activity with ${ }^{\mathrm{Ser}} 203_{\mathrm{Ala}}$ was 8 -fold lower while that of ${ }^{\mathrm{Ser}} 226_{\mathrm{Ala}}$ was about half of that of GRwt. Interaction of Ser $211_{\text {Ala }}$ with PPP2R3C was completely abolished suggesting that decreased phosphorylation of Ser $211_{\mathrm{Ala}}$ perturbed this interaction. Furthermore, contact occurred only in the presence of DEX indicating that the conformational change induced by ligand binding is an important step in the interaction with PPP2R3C. We next determined the function of the two nuclear receptor recognition motifs of PPP2R3C in GR interaction (Figure 2). One motif is located between aa 99-103 and the second between aa 248-252. Deletion of the motif between aa 1-103 eliminated binding to GR when compared with PPP2R3C 1-253 in which both motifs ( LWFLL \& LDDLL) were intact. Also interaction was possible only in the presence of ligand. This suggests that the specific conformation induced by ligand bound GR is a prerequisite for this interaction. Of the two nuclear receptor recognition motifs, the one between aa 103-253 appears to determine interaction with GR. The expression and purification of CREB and PPP2R3C used in de-phosphorylation analysis is shown in Figure 3A. We have previously demonstrated that in the negative feedback regulation of the GR gene, CREB-P was de-phosphorylated by GR-DEX complexes [7]. However, the mechanism by which this occurred was not clear then. After establishing that the nuclear receptor recognition motifs in PPP2R3C were indeed functional, we performed in vitro experiments that demonstrate the direct role of GR-DEX complex in recruiting PPP2R3C to de-phosphorylate CREB-P (Figure 3B). We expressed CREB, a mutant variant of the human CREB protein that contains a serine to alanine mutation corresponding to amino acid 133 (CREB-133), GR and PPP2R3C in bacteria using the PRSET system and the in vitro phosphorylated CREB-P for the dephosphorylation assays (Figure $3 A$ ). Increasing the quantity of GR in the presence of PPP2R3C had no effect on the level of CREB-P de-phosphorylation in the absence of ligand with T47D cell extract in this reconstitution assay. De-phosphorylation of CREB-P increased with increasing amounts of GR only in the presence of DEX in reconstitution with T47D cell extract. With this analysis, we established the mechanism by which CREB-P was de-phosphorylated by GR-DEX complexes by in vitro reconstitution. An early study with rat liver showed that the PP2A holoenzyme de-phosphorylated CREB-P and regulated transcription from the PEPCK promoter [10]. CREB directly interacted with GR and its recruitment by GR-DEX complexes was defined by its phosphorylation status [7]. 


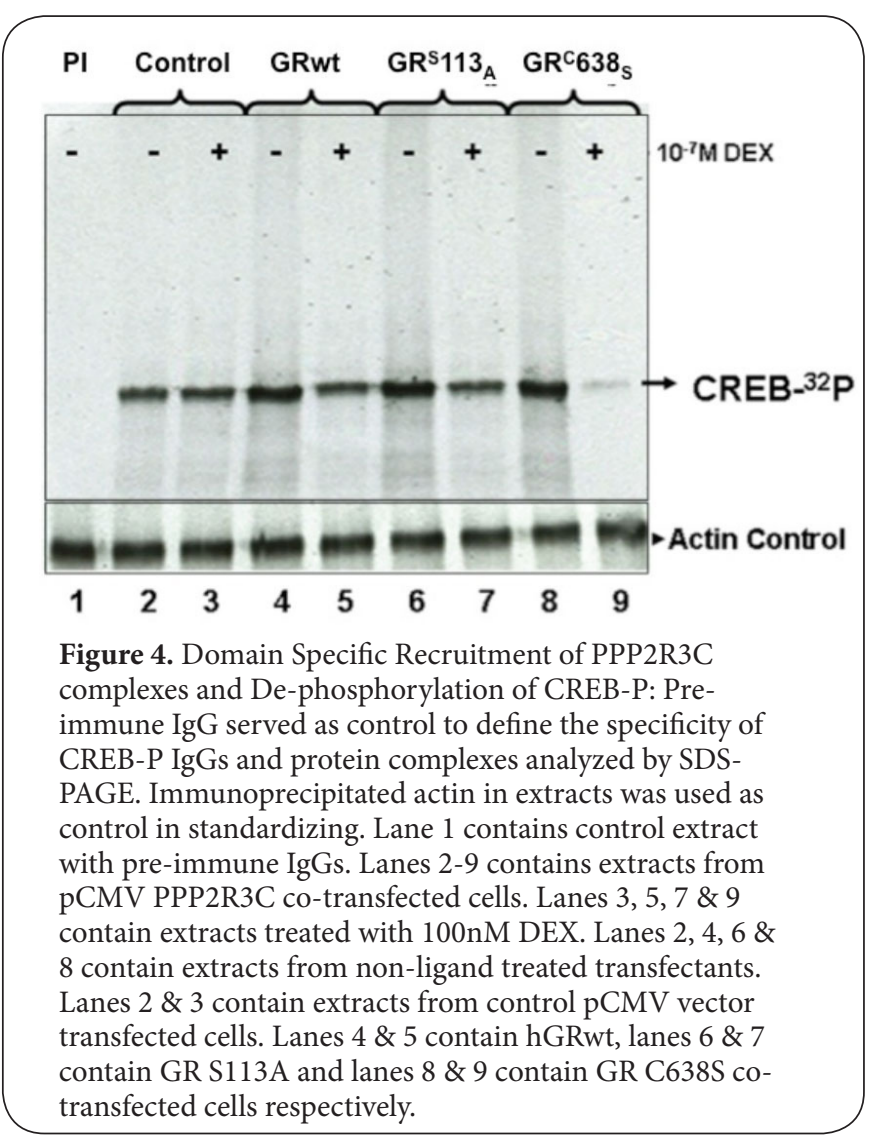

Figure 3B shows that increasing amounts of $G R$ recruiting PPP2R3C was more efficient in de-phosphorylating CREB-P by reconstitution with T47D cell extract in the presence of ligand demonstrating that hormone-bound GR is required.

\section{CREB-P is de-phosphorylated by GR-DEX recruited PPP2R3C complexes}

We established previously that a phosphatase captured by ligand bound GR, bound to the negative feedback regulatory response element (FBRE) of the GR gene, de-phosphorylated CREB-P [7]. The domain structure of $h G R$ and specific amino acid substitution are shown for reference in Figure 1A. As results from mammalian two-hybrid assays showed that $G R$ Ser113Ala interacted with PPP2R3C similar to GRwt while Ser $203_{\mathrm{Ala}^{\prime}}$ Ser $211_{\mathrm{Ala}}$ and ${ }^{\mathrm{Ser}} 226_{\mathrm{Ala}}$ (Figure 4), were less efficient in their interaction with PPP2R3C, we transfected HeLa cells with GRwt (Figure 4B lanes 4, 5), Ser $113_{\text {Ala }}$ (lanes 6, 7), Cys638 (lanes 8,9) and PPP2R3C expression vectors. Transfected cells were then purified using GR antibodies and incubated with

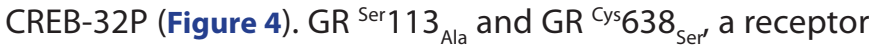
with increased potential to bind DEX and DNA and activate transcription, showed significant variations in their abilities to de-phosphorylate CREB-P. ${ }^{\text {Ser }} 113_{\text {Ala }}$ did not disrupt receptor function and de-phosphorylation of CREB-P in the presence of DEX was comparable to that of GRwt (lanes 4,5). In particular, de-phosphorylation of CREB-P was enhanced by PPP2R3C-GR

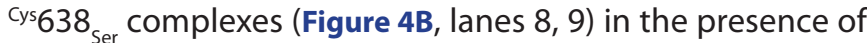
DEX. These results suggest that PPP2R3C contacts multiple sites in the GR N-terminal AF-1 domain as well as the HBD. Based on the above results, we used GST pull-down assays to determine which regions of the GR interacted with PPP2R3C (Figure 5A). GRwt interaction with PPP2R3C was enhanced in the presence of DEX when compared with control (lanes 1-4). Interactions between N-terminal GR 1-420 (lane 5) and GR 76-262 (lane 9) were only slightly weaker and not dependent on ligand. Just the GR DNA-binding domain (DBD) (lane 6) was not sufficient for interaction with PPP2R3C (Figure 5A). GR HBD showed strong affinity for PPP2R3C only in the presence of DEX (Figure $5 \mathrm{~A}$, lanes 7 and 8). These results indicate that PPP2R3C binding to GR can now be located to aa 76-262 in the AF-1 region in the absence of DEX as well as to the HBD in the presence of DEX. To further substantiate these results we performed in vitro protein-protein interaction assays using GST-GR substitution mutants involved in recruiting ${ }^{35} \mathrm{~S}-\mathrm{PPP} 2 \mathrm{R} 3 \mathrm{C}$. In the in vitro protein-protein assay controls included extracts from GST control and extracts in the absence and presence of 100nM DEX to demonstrate the ligand and domain specificity. In vitro results support the in vivo data of CREB-P de-phosphorylation by GR-DEX-PPP2R3C complexes. GST GR ${ }^{\text {Ser }} 113_{\text {Ala }}$ and GST-GR Ser $141_{\text {Ala }}$ showed the same capacity to recruit PPP2R3C as GST-GRwt (lanes1-9) in the presence of DEX (lanes 5, 7, 9\& 11 respectively). GST-GR Ser203 $3_{\text {Ala }}$ (lanes $10 \& 11$ ), GST-GR Ser $211_{\text {Ala }}$ (lanes $12 \& 13$ ) and GST-GR ${ }^{\text {Ser } 226} 6_{\text {Ala }}$ (lanes $14 \& 15$ ) were inhibited in contacting PPP2R3C as changes to alanine disrupted interaction in the presence of DEX when compared with GRwt (lanes 4 \& 5). Even though ${ }^{\text {Ser }} 203_{\text {Ala }}$ interaction with PPP2R3C was slightly hindered in the presence of DEX, ${ }^{\text {Ser }} 211_{\mathrm{Ala}}$ and ${ }^{\mathrm{Ser}} 226_{\mathrm{Ala}}$ were the most affected suggesting that PPP2R3C nuclear receptor motif between aa 103-253 contacts Ser 211 and Ser 226 in the AF-1 domain of the GR in the presence of DEX (Figure 5B).

\section{PPP2R3C knockdown increases GR expression and transcription activation}

The FBRE crucial for the negative regulation by GR-DEX complexes has two CREs and two nGREs [7]. We examined the role of the FBRE in PPP2R3C mediated suppression of transcription in HeLa cells by transfection and treatment with various ligands (Figure 6). The assay included control HeLa cells co-transfected with the reporter and treated with the liagands as shown in Figure 6 for comparison. Reporter activity was similar in control Hela and GRwt transfected cells following the treatments respectively, as HeLa cells do express some GR [7]. DEX suppressed reporter activity alone or in combination with cAMP. Here, GR-DEX bound to the nGRE decreased CAMP stimulated transcriptional activation by $100 \%$ (Figure 6). This was due to a decreased level of CREB binding in the presence of GR-DEX as previously reported [7]. Okadaic acid (OKA), a phosphatase inhibiter, alone inhibited cellular phosphatases and so prevented dephosphorylation of CREB-P, 
$5 \mathrm{~A}$

5B

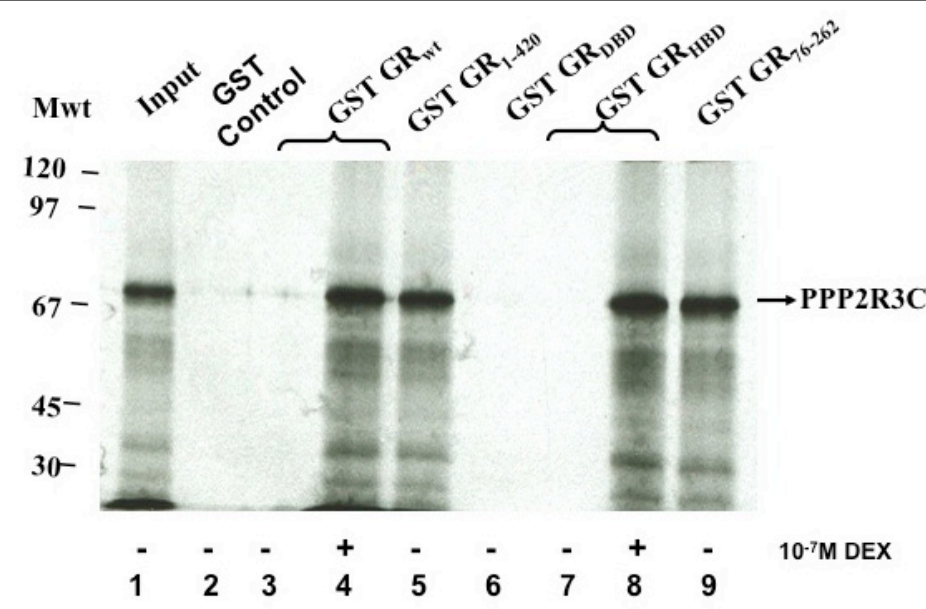

GST

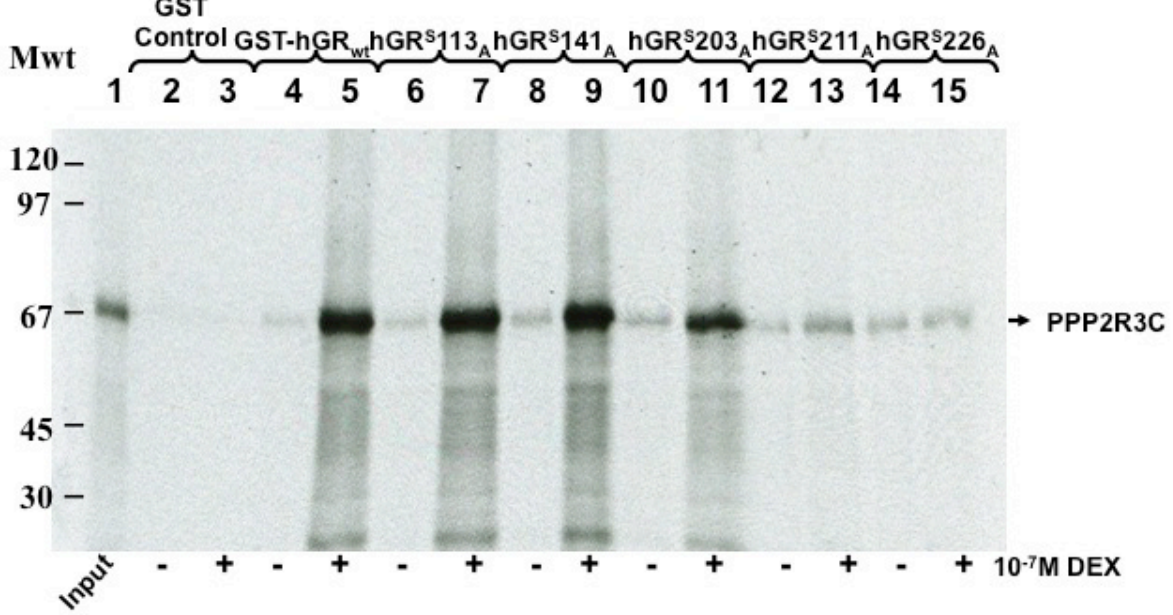

Figure 5A. In vitro interaction of ${ }^{35}$ S-PPP2R3C with GST-GRWT, GST-GR1-420, GST-GRDBD, GST-GRHBD and GSR-GRAF-1. 5B. Domain specific recruitment of PPP2R3C by hGR-DEX complexes.

which increased luciferase activity. This increase in transcription was substantial compared to the levels observed with cAMP derivatives treatment of the transfectant. Transcription activity was reduced by more than half when cells were treated with DEX and OKA (Figure 6, Hela Control \& pcDNA1 hGRwt). Here, GR-DEX bound to the $n G R E$ in the FBRE suppressed reporter activity by diminishing the transactivation by CREB-P. The CREBP effect in turn is due to the removal of CREB-P from the bound CREs by de-phosphorylation of CREB-P by specific phosphatase recruited by the adjacent $n$ GRE bound GR-DEX complexes. The addition of CAMP to OKA treated cells had a synergistic effect on luciferase activity. Not only was there inhibition of phosphatase, maintaining proteins in active phosphorylated forms, but also CAMP stimulated CREB induced transcriptional activation through binding to the two CREs. While the HBD was not necessary to recruit PPP2R3C, it is crucial perhaps to maintain the GR in a proper conformation once ligand binding has taken place. To understand the transcriptional function the chimeras of PPP2R3C-GR DBD and GR DBD PPP2R3C were constructed in pcDNA expression vectors using primers (Table 2). The function of FBRE was clearly demonstrated when cells were transfected with either PPP2R3C alone or the C-terminal tagged PPP2R3C-GR DBD (Figure 6). Reporter activity was significantly silent in CAMP treated cells as opposed to control and GRwt transfected cells. OKA alone did not have the same effect as with GR wild type confirming our hypotheses that GR-DEX complex specified recruitment of PPP2R3C. Overexpression of PPP2R3C decreased luciferase activity by overriding GR recruitment with OKA alone or in combination with DEX suggesting the suppression of regulation by GR. Co-transfection of an $\mathrm{N}$-terminal tagged GR DBD-PPP2R3C chimera did not change results (data not shown). This shows that both-CREB effect as well as the GR-DEX effect-are decoupled. The same synergistic effect was observed in OKA and cAMP treated cells. We next investigated the effect of knocking down PPP2R3C on GR level by Western blotting (Figure 7). Knockdown of PPP2R3C was efficient and enhanced GR expression, a direct evidence 


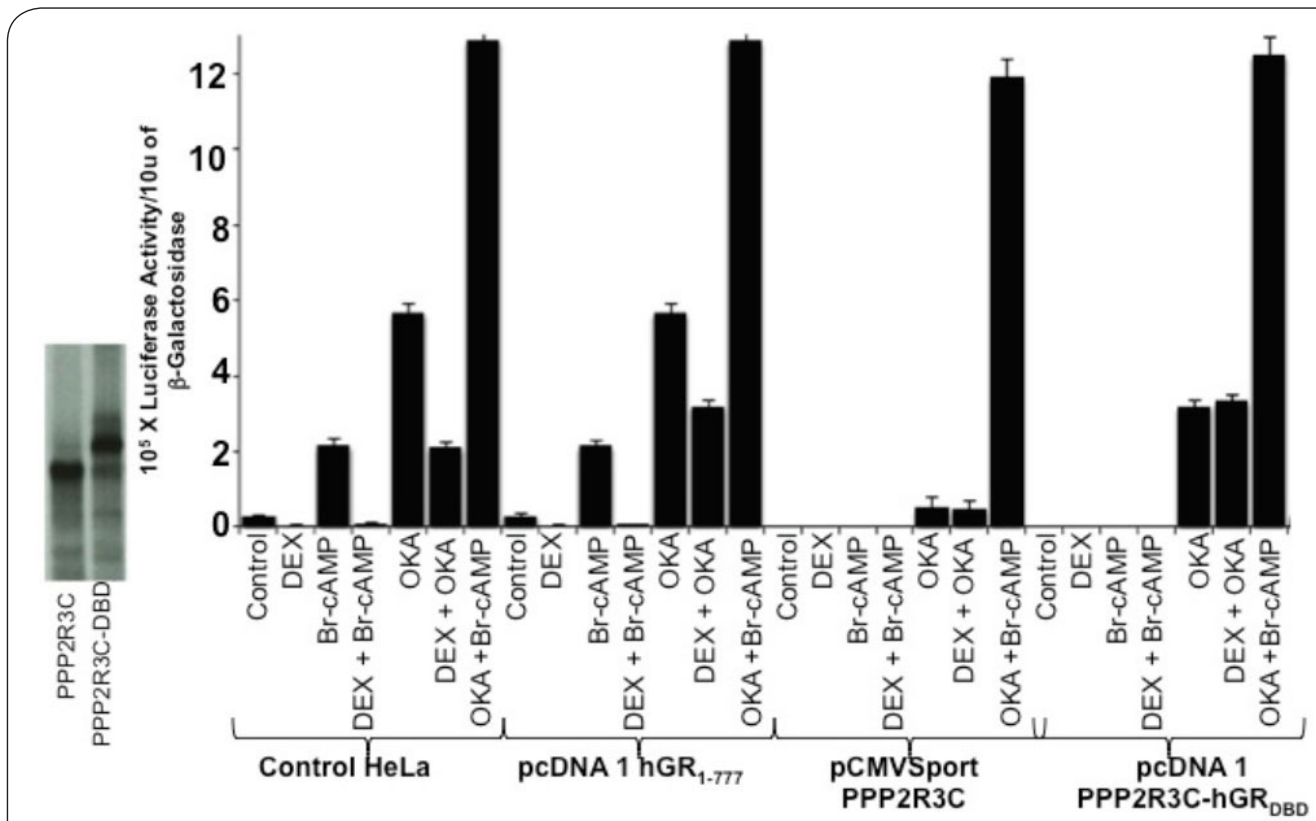

Figure 6. Analysis of GR gene feedback regulation and PPP2R3C mediated suppression in HeLa cells.

$7 \mathrm{~A}$
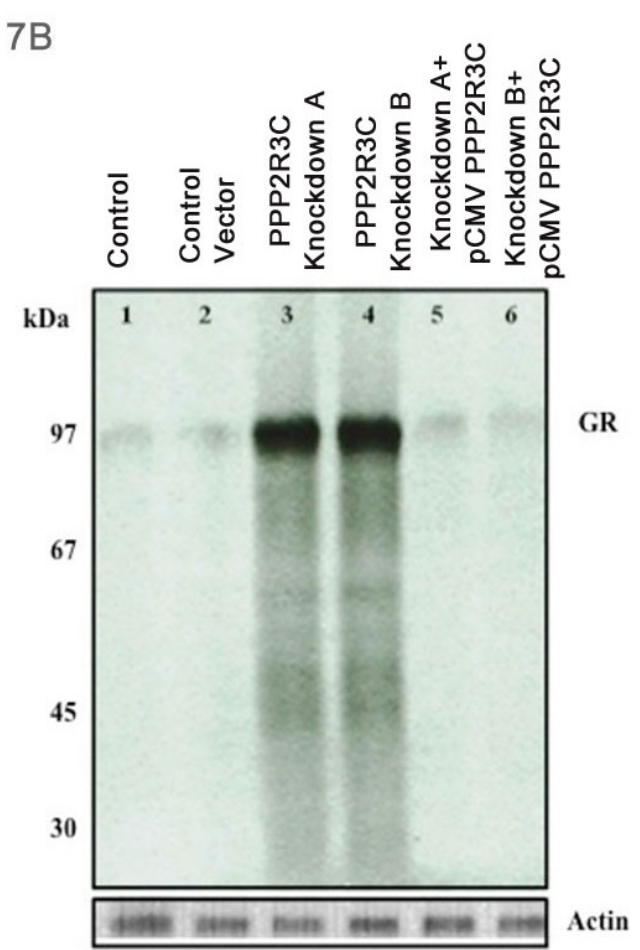

Figure 7A. Knockdown and Recue of PPP2R3C: For knockdown and rescue of PPP2R3C in HeLa cells, whole cell extracts were prepared from control HeLa and G418 selected PPP2R3C knockdown HeLa cells from two different colonies, A and B. Control vector selected HeLa cells served as negative control. Actin was used to monitor level of identical amounts of protein. Cell extracts were prepared as described used in Western blotting with antibodies against GR, PPP2R3C and actin. 7B. Immunoblotting of GR and PPP2R3c in Knockdown cells: ${ }^{35} \mathrm{~S}$ Methionine labeled cell extracts from control, PPP2R3C knockdown A and B, and PPP2R3C rescued knockdown cells were analyzed by immunoprecipitation using GR IgGs or control anti-actin IgGs. Rescue of PPP2R3C knockdown A and PPP2R3C knockdown B cells was by introduction of pCMV Sport6 PPP2R3C (lanes 5 \& 6). 


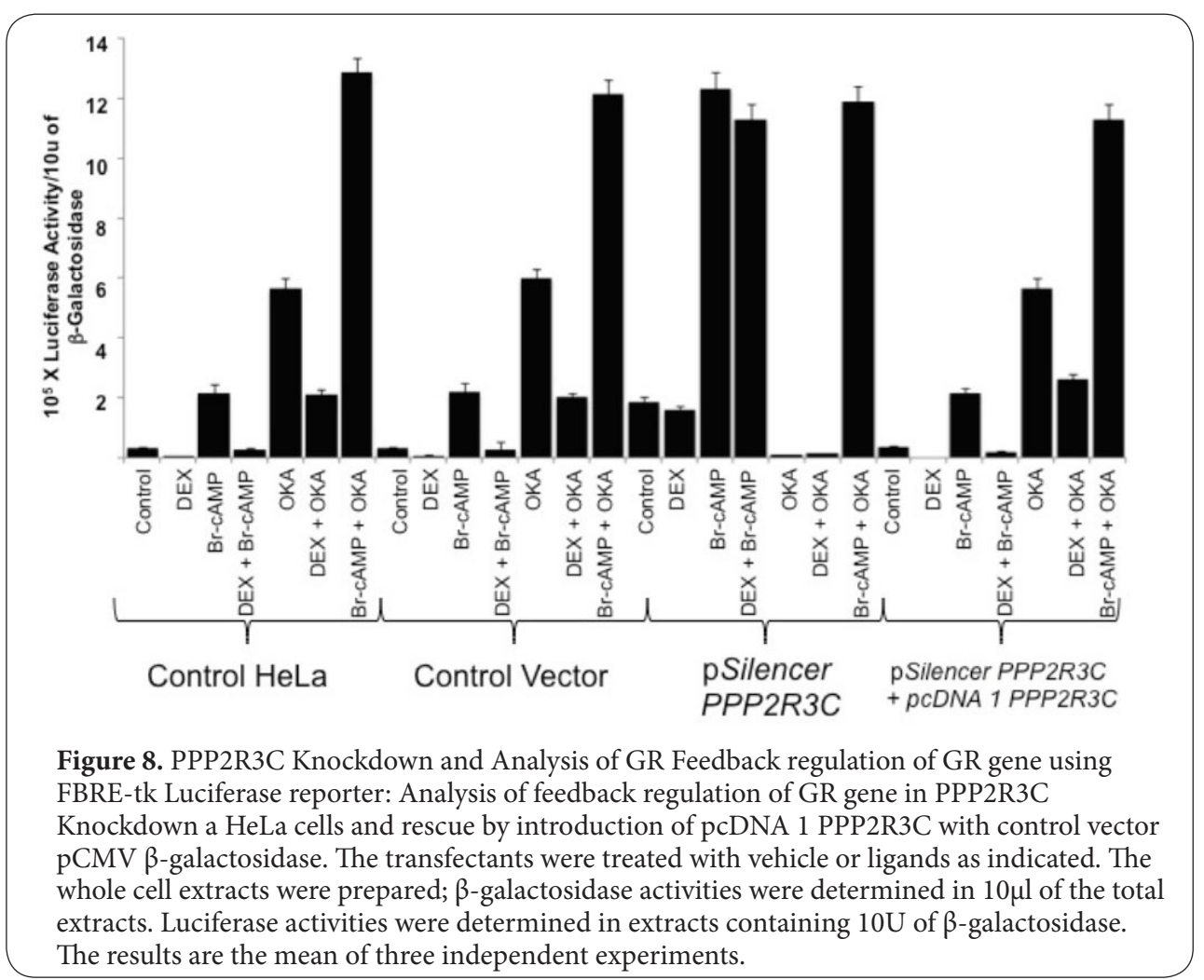

for the specificity of PPP2R3C subunit of PP2A in ligand mediated GR gene down regulation. This was the result of CREB-P activity where PPP2R3C knockdown prevented dephoshphorylating CREB-P maintaining it in its active form bound to GR gene regulatory sites. Inhibition of CREB-P dephosphorylation also increased GR level [7]. To determine the knockdown effect of PPP2R3C, equivalent quantities of total extracts from control cells, total extracts from cells of PPP2R3C knockdown A colonies, total extracts of control vector transfected and selected $\mathrm{G} 418$ resistant colonies and extracts from cells of PPP2R3C knockdown $B$ colonies were resolved by SDS-PAGE and transferred onto Immobilon $P$ membranes. Respective regions pertinent to the molecular weight of the factors were probed separately using specific antibodies to GR, PPP2R3C and actin respectively and visualized as described in experimental section (Figure 7A). The knockdown effect of PPP2R3C is convincingly shown in the high levels of GR expression in knockdown A \& B cells by Western compared to the control cell extracts (Figure 7A). This increased GR expression coincided with the knockdown of PPP2R3C expression shown in the Western probed with anti-PPP2R3C IgGs. The control lanes in Western probed with anti-actin IgGs demonstrate that equal amounts of extracts were used to demonstrate the knockdown effect (Figure 7A). To further elucidate the knockdown of PPP2R23C, we performed knockdown and rescue experiments in control and PPP2R3C knockdown cells by Western blotting using anti GR IgGs. As internal control and to determine equal amounts of extracts were used in this assay antiactin IgGs were used as controls. The levels of GR expression in control cell is shown Figure 7B, lane 1. As additional control to measure the GR expression, extracts from control vector transfected cells shows similar levels as non-transfected cells (Figure 7B, lane 2). The extracts of PPP2R3C knockdown cells A \& $B$ (Figure 7 , lanes $3 \& 4$ respectively) show that in these cells the GR expression is highly elevated. However, in identical cells from the same colonies PPP2R3C overexpressing, the GR expression was diminished to basal levels as observed with the controls (Figure 7B, lanes $5 \& 6$ respectively). GR expression was not inhibited in PPP2R3C knockdown cells and rescue of PPP2R3C by transfection of PPP2R3C expression vector reversed the knockdown effect in GR expression (Figure 7B). By further expanding our investigation we found significant differences that confirmed that PPP2R3C was indeed recruited by GR-DEX to regulate transcription (Figure 8). This was further confirmation as PPP2R3C contains two nuclear receptor recognition motifs. Knocking down PPP2R3C increased transcription activation from the FBRE promoter in the presence of CAMP alone 6-fold and in combination with DEX 11-fold when compared to controls. In this case, PPP2R3C was prevented from de-phosphorylating CREB-P and GR recruitment of PPP2R3C was hindered. This conclusion is supported by the fact that rescue of PPP2R3C restored function and response to levels observed with control HeLa cells. The absence of luciferase activity with OKA in PPP2R3C knockdown cells provides additional weight 
in support of this theory, as OKA in itself does not induce transcription. Whencombined with OKA, cAMP stimulated luciferase activity was the same as with controls, indicating that the same synergistic effect. Thus knocking down PPP2R3C abolished all normal response mediated by PPP2R3C.

\section{Discussion}

The negative regulation of the GR gene by GR-DEX complexes involves the recruitment of a nuclear phosphatase, PP2A consisting of a structural subunit $A$, a catalytic subunit $C$, and a regulatory subunit $B$, which de-phosphorylates CREB-P $[7,12]$. We have identified this regulatory subunit $B$ of the nuclear protein phosphatase PP2A as PPP2R3C, with an apparent molecular weight of $50 \mathrm{kDa}$. PPP2R3C is of particular interest as it contains two nuclear receptor recognition motifs and is highly expressed in glucocorticoid target tissues with expression being highest in testis and kidney (data not shown). In this study, we used the FBRE that has two CREs and two $n G R E s$. While the regulatory subunit of PP2A, PPP2R3C directly interacts with the GR and de-phosphorylates CREB-P, another phosphatase, PP5, only associates with the GR-hsp 90 complex [14] to suppress GR induced gene expression by preventing nuclear translocation [15]. The GR is a phosphoprotein and specific serines within the N-terminus, GR Ser203, ser2 211 and ser226, are targets of various kinases and phosphatases [16-18]. Serines 203 and 211 induce conformational changes that facilitate interactions with cofactors [19] while replacing Ser 226 with an alanine affects transcriptional response [20]. The importance of cysteine 638 located in the GR HBD, a region that determines binding to heat shock protein $90[21,22]$ is reflected by the fact that changing this cysteine to serine generates a ligand bound receptor that is more effective at displacing factors associated with the inactive form [22]. Here we show that PPP2R3C interacts with the region of GR $\mathrm{HBD}$ comprising of ${ }^{\mathrm{Cy}} \mathrm{6} 638$ to maintain CREB-P. The two nuclear receptor recognition motifs in PPP2R3C between aa 103-253 that contact specific serines in the GR AF-1 indicate the role of PPP2R3C in the feedback regulation of human GR gene containing FBRE in target tissues.

Improper formation, overexpression and incorrect subcellular localization of the PP2A holoenzyme are factors in various types of cancer $[\mathbf{2 3}, \mathbf{2 4}]$. It has been speculated that the phosphatase PP5 directly de-phosphorylates GR $[15,19]$. However, further analyses revealed that PP5 only participated in the shuttling of the GR. The holoenzyme regulates the expression of the estrogen receptor by affecting $\mathrm{mRNA}$ stability [25]. Although the HBD is necessary for PPP2R3C interaction, the AF-1 region also plays a role. This is in contrast to the androgen receptor where PPP2R3C bound a receptor in which either the AF-1 or the DBD was deleted [25]. Furthermore, deletion of the HBD abolished PPP2R3C binding.

\section{Conclusion}

Our investigation delineates a role of PPP2R3C in GR-mediated negative regulation where the various regulatory subunits that make up the PP2A holoenzyme have distinct functions. The complexity of gene regulation by glucocorticoids is illustrated in studies where knocking down CREB decreased GR levels while knocking down histone deacetylase-6 increased it [7] Furthermore, in this study we show that knocking down PPP2R3C increased GR level implying that such variations contribute to the tissue specificity of $G R$ regulation of gene expression. This is further reflected by the fact that a GR AF-1 specific phosphatase (GeneBank Accession \# AF74498), which varies considerably from PPP2R3C, does not de-phosphorylate CREB-P. These results have potential to be useful in the designing of diagnostic regimen for patients who become resistant to glucocorticoid therapy during the course of their treatment [26]. Resistance, which is the result of a loss in GR function, due to down-regulation of GR expression leads to decreased sensitivity to Dex, a serious complication in the treatment of arthritis and severe asthma.

\author{
Abbreviations \\ AF-1: activation function 1 \\ AF-2: activation function 2 \\ CRE: cAMPresponse element \\ CREB: CAMPresponse element binding protein \\ DEX: dexamethasone \\ Bt2-cAMP: dibutyryl cAMP \\ GR: human glucocorticoid receptor \\ DBD: DNA binding domain \\ nGRE: negative glucocorticoid response element \\ FBRE: feedback regulatory element \\ PPP2R3C: regulatory subunit of PP2A \\ DCC: dextrane coated charcoal \\ FBS: fatal bovine serum \\ GST: glutathione S-transferase
}

Competing interests

The authors declare that they have no competing interests.

\section{Acknowledgement}

I thank Dr. Nalini Warriar for critical reading of the manuscript. I am grateful to Dr. Pedro de Campos-Lima for encouraging discussions.

\section{Publication history}

Editors: Liping Gu, South Dakota State University, USA. Jan Willem Voncken, Maastricht University Medical Center, Netherlands.

Dinesh A. Nagegowda, CSIR-Central Institute of Medicinal and Aromatic Plants, India.

Received: 04-Jun-2013 Revised: 11-Jul-2013

Re-Revised: 05-Aug-2013 Accepted: 07-Aug-2013

Published: 17-Aug-2013

\section{References}

1. Vale W, Spiess J, Rivier C and Rivier J. Characterization of a 41-residue ovine hypothalamic peptide that stimulates secretion of corticotropin and beta-endorphin. Science. 1981; 213:1394-7. I Article I PubMed

2. Dallman MF, Jones MT, Vernikos-Danellis J and Ganong WF. Corticosteroid feedback control of ACTH secretion: rapid effects of bilateral adrenalectomy on plasma ACTH in the rat. Endocrinology. 
Govindan \& Seguin Molecular Biology and Genetic Engineering 2013,

http://www.hoajonline.com/journals/pdf/2053-5767-1-2.pdf

1972; 91:961-8. | Article | PubMed

3. Schilling K, Schmale H, Oeding P and Pilgrim C. Regulation of vasopressin expression in cultured diencephalic neurons by glucocorticoids. Neuroendocrinology. 1991; 53:528-35. | Article | PubMed

4. Imai E, Miner JN, Mitchell JA, Yamamoto KR and Granner DK. Glucocorticoid receptor-cAMP response element-binding protein interaction and the response of the phosphoenolpyruvate carboxykinase gene to glucocorticoids. J Biol Chem. 1993; 268:5353-6. | Article | PubMed

5. Eberwine, JH, Roberts, JL. Glucocorticoid regulation of proopiomelanocortin gene transcription in the rat pituitary. J Biol Chem. 1984; 259:2166-2170. | Pdf

6. LeClerc S, Palaniswami R, Xie BX and Govindan MV. Molecular cloning and characterization of a factor that binds the human glucocorticoid receptor gene and represses its expression. J Biol Chem. 1991; 266:17333-40. | Article | PubMed

7. Govindan MV. Recruitment of cAMP-response element-binding protein and histone deacetylase has opposite effects on glucocorticoid receptor gene transcription. J Biol Chem. 2010; 285:4489-510. | Article | PubMed Abstract | PubMed Full Text

8. Miller AL, Webb MS, Copik AJ, Wang Y, Johnson BH, Kumar R and Thompson EB. p38 Mitogen-activated protein kinase (MAPK) is a key mediator in glucocorticoid-induced apoptosis of lymphoid cells: correlation between p38 MAPK activation and site-specific phosphorylation of the human glucocorticoid receptor at serine 211 . Mol Endocrinol. 2005; 19:1569-83. | Article | PubMed

9. Guardiola-Diaz HM, Kolinske JS, Gates LH and Seasholtz AF. Negative glucorticoid regulation of cyclic adenosine 3', 5'-monophosphatestimulated corticotropin-releasing hormone-reporter expression in AtT-20 cells. Mol Endocrinol. 1996; 10:317-29. | Article | PubMed

10. Wadzinski BE, Wheat WH, Jaspers S, Peruski LF, Jr., Lickteig RL, Johnson $\mathrm{GL}$ and Klemm DJ. Nuclear protein phosphatase 2A dephosphorylates protein kinase A-phosphorylated CREB and regulates CREB transcriptional stimulation. Mol Cell Biol. 1993; 13:2822-34. | Article | PubMed Abstract | PubMed Full Text

11. Janssens $V$ and Goris J. Protein phosphatase 2A: a highly regulated family of serine/threonine phosphatases implicated in cell growth and signalling. Biochem J. 2001; 353:417-39. | Article | PubMed Abstract | PubMed Full Text

12. Hubbard MJ and Cohen P. Targeting subunits for protein phosphatases. Methods Enzymol. 1991; 201:414-27. | Article | PubMed

13. Warriar N, Yu C and Govindan MV. Hormone binding domain of human glucocorticoid receptor. Enhancement of transactivation function by substitution mutants M565R and A573Q. J Biol Chem. 1994; 269:290105. | Article | PubMed

14. Silverstein AM, Galigniana MD, Chen MS, Owens-Grillo JK, Chinkers $\mathrm{M}$ and Pratt WB. Protein phosphatase 5 is a major component of glucocorticoid receptor.hsp90 complexes with properties of an FK506binding immunophilin. J Biol Chem. 1997; 272:16224-30. | Article | PubMed

15. Dean DA, Urban G, Aragon IV, Swingle M, Miller B, Rusconi S, Bueno M, Dean NM and Honkanen RE. Serine/threonine protein phosphatase 5 (PP5) participates in the regulation of glucocorticoid receptor nucleocytoplasmic shuttling. BMC Cell Biol. 2001; 2:6. | Article | PubMed Abstract | PubMed Full Text

16. Somers JP and DeFranco DB. Effects of okadaic acid, a protein phosphatase inhibitor, on glucocorticoid receptor-mediated enhancement. Mol Endocrinol. 1992; 6:26-34. | Article | PubMed

17. Orti E, Mendel DB, Smith LI and Munck A. Agonist-dependent phosphorylation and nuclear dephosphorylation of glucocorticoid receptors in intact cells. J Biol Chem. 1989; 264:9728-31. | Article | PubMed

18. Tienrungroj W, Sanchez ER, Housley PR, Harrison RW and Pratt WB. Glucocorticoid receptor phosphorylation, transformation, and DNA binding. J Biol Chem. 1987; 262:17342-9. | Article | PubMed

19. Wang Z, Chen W, Kono E, Dang T and Garabedian MJ. Modulation of glucocorticoid receptor phosphorylation and transcriptional activity by a C-terminal-associated protein phosphatase. Mol Endocrinol. 2007; 21:625-34. | Article | PubMed

20. Chen W, Dang T, Blind RD, Wang Z, Cavasotto CN, Hittelman AB, Rogatsky I, Logan SK and Garabedian MJ. Glucocorticoid receptor phosphorylation differentially affects target gene expression. Mol Endocrinol. 2008; 22:1754-66. | Article | PubMed Abstract | PubMed Full Text

21. Cadepond F, Schweizer-Groyer G, Segard-Maurel I, Jibard N, Hollenberg SM, Giguere V, Evans RM and Baulieu EE. Heat shock protein 90 as a critical factor in maintaining glucocorticosteroid receptor in a nonfunctional state. J Biol Chem. 1991; 266:5834-41. | Article | PubMed

22. Yu C, Warriar N and Govindan MV. Cysteines 638 and 665 in the hormone binding domain of human glucocorticoid receptor define the specificity to glucocorticoids. Biochemistry. 1995; 34:14163-73. | Article I PubMed

23. Ruediger R, Pham HT and Walter G. Disruption of protein phosphatase $2 A$ subunit interaction in human cancers with mutations in the $A$ alpha subunit gene. Oncogene. 2001; 20:10-5. | PubMed

24. Wang GL, lakova P, Wilde $M$, Awad $S$ and Timchenko NA. Liver tumors escape negative control of proliferation via PI3K/Akt-mediated block of C/EBP alpha growth inhibitory activity. Genes Dev. 2004; 18:912-25. | Article | PubMed Abstract | PubMed Full Text

25. Keen JC, Zhou Q, Park BH, Pettit C, Mack KM, Blair B, Brenner K and Davidson NE. Protein phosphatase 2A regulates estrogen receptor alpha (ER) expression through modulation of ER mRNA stability. J Biol Chem. 2005; 280:29519-24. | Article | PubMed

26. Yang CS, Xin HW, Kelley JB, Spencer A, Brautigan DL and Paschal BM. Ligand binding to the androgen receptor induces conformational changes that regulate phosphatase interactions. Mol Cell Biol. 2007; 27:3390-404. | Article | PubMed Abstract | PubMed Full Text

\section{Citation:}

Govindan MV and Seguin C. Final steps in the feedback regulation of human glucocorticoid receptor gene and role of nuclear protein phosphatase $2 \mathrm{~A}$. Mol Biol Genet Eng. 2013; 1:2.

http://dx.doi.org/10.7243/2053-5767-1-2 